\title{
Psychiatric rehabilitation in Latin America: challenges and opportunities
}

\author{
J. M. Uribe-Restrepo ${ }^{1,2,3 *}$, M. L. Escobar ${ }^{4,5}$ and L. Cubillos ${ }^{6}$ \\ ${ }^{1}$ Fundación Santa Fe de Bogotá, Colombia \\ ${ }^{2}$ GESESM (Grupo de Estudios Socioeconómicos en Salud Mental), Bogotá, Colombia \\ ${ }^{3}$ Public Mental Health Consultant, Independent, Bethesda, MD, USA \\ ${ }^{4}$ Health Economist \& Policy Analyst, Independent, Alexandria, VA, USA \\ ${ }^{5}$ Former Health Practice Latin America \& The Caribbean, The World Bank, Washington, DC, USA \\ ${ }^{6}$ Department of Psychiatry, Dartmouth Hitchcock Medical Center, Dartmouth College, Lebanon, PA, USA
}

\begin{abstract}
Comprehensive psychiatric rehabilitation programs in Latin America have been designed across several countries in the region without yet achieving full implementation. Facing an increasing burden of disease due to mental disorders, including alcohol and substance use disorders, the region has responded unevenly to the challenge. Moreover, low priority for mental health in national policies and insufficient funding for mental health services are common barriers for the much-needed mental health services reforms. Reestablishing a primary care community-based model of care has been a shared aspiration for most countries during the last two decades. Comprehensive models of psychiatric rehabilitation developed predominantly in high-income countries need to be culturally adapted to local contexts, while strengthening health systems research will provide evidence on the efficiency of locally designed interventions and on the critical milestones to succeed in the scaling up strategies. Increasing participation of patients and their families in the mental health delivery system is another key factor in order to ensure comprehensive patient-centred psychosocial rehabilitation programs in Latin America.
\end{abstract}

First published online 17 November 2016

Key words: Community mental health, primary care, psychiatric services, rehabilitation.

\section{Background}

Mental and substance use disorders have significantly contributed to the non-communicable burden of disease in Latin America, accounting for an estimated $10.9 \%$ of the total disability-adjusted life years in 2013 in the region (Whiteford et al. 2013; Institute for Health Metrics and Evaluation (IHME), 2015). Nevertheless, only about $1.5 \%$ of the total budget for health was allocated to mental health in these countries. Moreover, Latin American countries invested less in mental health care than countries of similar income level in other regions (Minoletti et al. 2012). The insufficiency and disparity in mental health funding (Razzouk et al. 2010; Gilbert et al. 2015) in the region serves as a major barrier to improving mental health services and expanding evidence-based psychiatric rehabilitation programs.

Latin America faces a steep rise in the burden of non-communicable diseases as well as a continuing burden from maternal illness and communicable diseases, such as the recent Zika and Chikungunya

* Address for correspondence: J. M. Uribe-Restrepo, MD, MPH, Public Mental Health Consultant, Independent, 6212 Wedgewood Road, Bethesda, MD 20817, USA.

(Email: miguel.uribe@gmail.com) virus epidemics. In addition, Latin America has an estimated $30 \%$ lifetime prevalence of physical and/or sexual intimate partner violence among ever-partnered women (World Health Organization, 2013). Violence often occurs before age 15, and the long-term consequences of early experience of violence are well documented in the scientific literature worldwide, including a higher prevalence of depression, suicide ideation and substance abuse. Harmful use of alcohol has also been identified as a major risk factor in the region; the average consumption of alcohol in Latin America is $50 \%$ higher than worldwide consumption (Rehm \& Monteiro, 2005), and men's alcohol abuse increases the likelihood of intimate partner violence (Abramsky et al. 2011). Finally, some countries in the region, e.g., Colombia and El Salvador, have also faced the continuing burden of decades of sociopolitical conflict and frequent natural disasters.

Thus, the challenge of responding to a changing epidemiological landscape, in which mental disorders have significantly increased in importance, will require the continuing transformation of health systems.

Latin America is a heterogeneous region comprising mostly middle-income countries, with an overall population of 634,387 million in 2015 and an annual population growth rate of $1 \%$ (World Population Prospects, 2015). It is an ethnically diverse region 
with a high level of income inequality (Gini Index= 41.9-53.7) (The World Bank, 2015) and social disparity. Health care delivery models vary widely, explained in part by differences in health systems' institutional organisation, financing and delivery of care arrangements. For example, while competition and multiple insurers characterise health systems in Colombia and Chile, those of Brazil, Costa Rica and Cuba are single payer systems. During the last decades of the previous century, political changes paved the way for structural reforms in health systems with the aim of achieving universal health coverage in the region (Atun et al. 2015). Important advances have been made across the region in achieving universal health coverage, but access to effective care and quality assurance need to improve (Wagstaff et al. 2015).

The World Health Organization/Pan American Health Organization has consistently brought to the policy debate for decades the need for mental health services reform in the region. Twenty-five years ago, the Caracas Declaration, endorsed by all Ministers of Health of the Americas, called for restructuring mental health systems by moving away from the psychiatric hospital-centred model to a community-based approach with emphasis on primary care (Organización Panamericana de la Salud/Organización Mundial de la Salud (Ops/Oms), 1990). The Caracas Declaration set the stage for a transformation of psychiatric services in Latin America and initiated a process of revision of mental health legislation in several countries.

During the 1990s, although some countries (e.g., Brazil, Costa Rica, Chile and Cuba) implemented national policies that expanded primary care services, the majority of Latin American health systems experienced stagnant growth of primary care services. Furthermore, mental health was rarely on the political and media agenda of health sector reform, and community mental health care and psychiatric rehabilitation were neglected in national health programs. As a result, mental health care was not comprehensively included in the publicly financed benefit plans introduced by the reforms in several Latin American countries.

In 2013, the Brasilia Consensus reiterated the need to expand a human rights perspective and promote psychosocial rehabilitation programs (Panamerican Health Organization (PAHO), 2013). It stressed again the need to evolve from a hospital-centred into a community- and primary care-based model.

Building on the spirit of the Caracas declaration and the Brasilia Consensus, many countries in Latin America have revised and updated laws and regulations to improve mental health care delivery. In some cases a new National Health Law was introduced. As an example of political achievement, in 2013 Colombia enacted a new mental health law that contains provisions to build a community-based rehabilitation model (Ley de Salud Mental, 2013). This Law states the need to adapt the delivery of services to patient preferences, introduces a strong framework for community-based care, and obligates the Government to provide for social and labour inclusion of people suffering from mental disorders. Similar dispositions can be found in the recent mental health law in Peru, which also emphasises community-based treatment, mental health networks and psychiatric rehabilitation programs, including supported residential models (Ministerio de Salud del Perú, 2015). As in the past, the challenge for these countries is implementation.

Despite the legislative progress in several Latin American countries and the development of some community mental health services since the 1970s, the lack of financing and political support have prevented scaling up (Pan American Health Organization (PAHO), 2016). Thus, integrated care, community mental health and psychosocial rehabilitation have not yet been successfully implemented in the region on a large scale. Fortunately, primary care services are expanding and mental health services are starting to play a more prominent role (Macinko et al. 2007). Chile's program of detection and treatment of depression in primary care is an example of successful mental health policy design and implementation (Araya et al. 2009; Alvarado et al. 2012a). Other interesting mental health programs in the region have been introduced locally but have not scaled up nationally. Furthermore, most are not published and widely disseminated. Systematic evaluation efforts are rare, and the lack of rigorous effectiveness data limits comprehensive psychosocial rehabilitation and community-based mental care (Caldas De Almeida \& Cohen, 2008).

As an example of research advances, an instrument characterising and evaluating the degree of development of community-based models of networks delivering community care for people with severe mental disorders, the EvaRedCom-TMS (Evaluación de Redes de Servicios Comunitarios para Trastornos Mentales Severos [Assessment of Networks of Community Services for Severe Mental Disorders]) has been validated in Chile (Alvarado, 2007). Initial studies show promising results in terms of efficiency when comparing a more community-based network to a less communitybased network (Alvarado et al. 2012b).

\section{Psychiatric rehabilitation in Latin America}

Psychiatric rehabilitation interventions help people with severe mental disorders, such as schizophrenia, bipolar disorder and major depression, develop skills, 
supports and opportunities so that they can achieve social inclusion and participate fully as citizens in their communities. It requires community-based services with an interdisciplinary team approach. Psychiatric rehabilitation includes an array of psychosocial programs such as assertive community treatment, family psycho-education, supported housing and supported employment (Bond \& Drake, 2015). Latin America has examples of some of these elements in the home group care model in Argentina, the community mental health centres in Chile and the Psychosocial Community Centres in Brazil (Centros de Atenção Psicosocial-CAPS) (Minoletti et al. 2012).

Efforts have also been made to shorten the hospitalisation days for acute episodes. Day hospitals and partial hospitalisation have become common, but they do not address social inclusion. Although these programs have been an improvement over previous practices, they still fall short of effective rehabilitation for severe mental illness. The newer legislative frameworks, such as the aforementioned ones in Colombia and Peru, may enable the development of appropriate psychiatric rehabilitation programs.

To consolidate rehabilitation for severe mental illness in the region will require approaching mental health care systemically within the definition of Universal Health Coverage. Professionals must clearly identify and analyse the political and financial barriers as well as the enablers of the existence of psychosocial rehabilitation programs in the Latin American context. Building on the human rights perspective, strong multidisciplinary action in the region can form regional and national coalitions to introduce policy reforms and drive their implementation. Moreover, improvement of research capacity and international cooperation are also important steps to achieve parity for mental health (Caldas de Almeida, 2013). Strengthening research capabilities has been supported by national efforts and by the increasing role of international founders such as the National Institute of Mental Health and Grand Challenges Canada. However, more needs to be done in this area. The scientific evaluation and publication of results, as the example of the expansion of depression treatment in Chile shows (Razzouk et al. 2012), will make a stronger case among policy makers.

Models of care that have been successful in countries outside of Latin America, such as assertive community treatment or early psychosis treatment (Kane et al. 2015) must be adapted to local contexts. Latin America has a significant opportunity to advance the quality of implementation research because most of the existing evidence on community-based rehabilitation services stems from observational studies only. Other countries have adapted rehabilitation approaches by relying on lay workers. For example, the community-based intervention for people with schizophrenia and their caregivers study in India may provide a valuable example (Chatterjee et al. 2014). In adapting these models, training and ongoing supervision, as well as quality assurance, are key components (Silove \& Ward, 2014). Costs need to be systematically assessed in order to ensure continuity and sustainability. Strategic use of culturally-adapted technology - telepsychiatry, e-health consultation, e-training and mobile phone technologies - may enhance capacity.

\section{Opportunities for psychiatry rehabilitation}

Recent attention to global mental health, as well as a growing consensus to advance community-based mental health services, present opportunities in Latin America (Copeland et al. 2014; Kleinman et al. 2016). Several local programs are currently delivering patientcentred care, using an inter-disciplinary approach and emphasising community inclusion. Systematic evaluation could transform these efforts into national programs.

Culture, tradition and strong family bonds determine minimal geographic movement in Latin America. Consequently, families already provide caregiving and support, which could contribute to developing an effective psychiatric rehabilitation system. The importance of local cultural factors in the course of severe mental illness is illustrated by the better outcomes among people with schizophrenia in low- and middle-income countries compared with high-income countries, notwithstanding some controversy (Isaac et al. 2007; Cohen et al. 2008).

To expand psychiatric rehabilitation into national policies, activities must be imbedded in and aligned with other social programs that countries have already established and build on a trans-sector and horizontal approach (Eaton et al. 2014). Many countries in the region have already implemented housing, employment and vocational training programs that can be instrumental and/or complementary to a rehabilitation system. Leveraging the strengths of the government and/or private sector organisations leading those programs can facilitate consensus.

Empowerment of patients and their families as users and leaders of psychiatric rehabilitation programs is necessary to achieve widespread implementation. Families and patients have traditionally played a passive recipient role, which has unfortunately been compounded by the stigma and discrimination associated with mental and substance use disorders. To overcome stigma and achieve social inclusion will require meaningful participation and empowerment at different levels of the mental health care system, including policy planning (Drake et al. 2014). 


\section{Conclusion}

Creating systems of psychiatric rehabilitation for people with severe mental illness in Latin America will require strong leadership from government, mental health professionals, researchers, patients and families. Evidence-based models of rehabilitation, such as assertive community treatment, family psycho-education, supported housing and supported employment, should build on current services, resources and legislation, with adaptations to local conditions and cultures (Drake et al. 2014). Research evaluations using outcomes that patients value and costeffectiveness analyses will strengthen the policy case for psychiatric rehabilitation. Finally, training and tasksharing with lay health workers, families and patients may ensure continuity and sustainability of the programs.

\section{Acknowledgements}

We thank Dr Robert Drake for his valuable advice.

\section{Conflict of Interest}

None.

\section{Financial Support}

This research received no specific grant from any funding agency, commercial or not-for-profit sectors.

\section{References}

Abramsky T, Watts CH, Garcia-Moreno C, Devries K, Kiss L, Ellsberg M, Jansen HA, Heise L (2011). What factors are associated with recent intimate partner violence? Findings from the WHO multi-country study on women's health and domestic violence. BMC Public Health 11, 109.

Alvarado R (2007). Elaboración y validación de instrumento que describe y caracteriza las redes de servicios de salud mental para personas que padecen esquizofrenia. Revista Chilena de Salud Pública 11, 117-126. Retrieved 20 September 2016 from http://www.revistasaludpublica. uchile.cl/index.php/RCSP/article/view/2886.

Alvarado R, Rojas G, Minoletti A, Alvarado F, Domínguez C (2012a). Depression program in primary health care. The Chilean experience. International Journal of Mental Health 41, 38-47.

Alvarado R, Minoletti A, Torres-González F, MorenoKüstner B, Madariaga C, Sepúlveda R (2012b). Development of community care for people with Schizophrenia in Chile. International Journal of Mental Health 41, 48-61. Retrieved 20 September 2016 from http://www. tandfonline.com/doi/full/10.2753/IMH0020-7411410104.

Araya R, Alvarado R, Minoletti A (2009). Chile: an ongoing mental health revolution. Lancet 374, 597-598.
Atun R, Monteiro de Andrade LO, Almeida G, Cotlear D, Dmytraczenko T, Frenz P, García P, Gómez-Dantés O, Knaul F, Muntaner C, Braga de Paula J, Rígoli F, Castell-Florit Serrate P, Wagstaff A (2015). Health-system reform and universal health coverage in Latin America. Lancet 385, 1230-1247. Retrieved 13 June 2016 from http:// linkinghub.elsevier.com/retrieve/pii/S0140673614616469.

Bond GR, Drake RE (2015). The critical ingredients of assertive community treatment. World Psychiatry 14, 240-242.

Caldas de Almeida JM (2013). Mental health services development in Latin America and the Caribbean: achievements, barriers and facilitating factors. International Health 5, 15-18.

Caldas de Almeida JM, Cohen A (2008). Innovative Mental Health Programs in Latin America and the Caribbean. Pan American Health Organization (PAHO). http://www.paho. org/hq/index.php?option=com_content\&view=article\&id= 193\%3A2008-innovative-mental-health-programas\&catid= 1169\%3Anmh-mental-health-technical-documents\& Itemid $=40615 \&$ lang $=$ en

Chatterjee S, Naik S, John S, Dabholkar H, Balaji M, Koschorke M, Varghese M, Thara R, Weiss HA, Williams P, McCrone P, Patel V, Thornicroft G (2014). Effectiveness of a community-based intervention for people with schizophrenia and their caregivers in India (COPSI): a randomised controlled trial. Lancet 383, 1385-1394.

Cohen A, Patel V, Thara R, Gureje O (2008). Questioning an axiom: better prognosis for schizophrenia in the developing world? Schizophrenia Bulletin 34, 229-244.

Copeland J, Thornicroft G, Bird V, Bowis J, Slade M (2014). Global priorities of civil society for mental health services: findings from a 53 country survey. World Psychiatry 13, 198-200.

Drake RE, Binagwaho A, Martell HC, Mulley AG (2014). Mental healthcare in low and middle income countries. British Medical Journal 349, g7086. Retrieved 27 November 2014 from http://www.bmj.com/content/349/bmj.g7086?etoc=.

Eaton J, Kakuma R, Wright A, Minas H (2014). A position statement on mental health in the post-2015 development agenda. International Journal of Mental Health Systems 8, 28.

Gilbert BJ, Patel V, Farmer PE, Lu C (2015). Assessing development assistance for mental health in developing countries: 2007-2013. PLoS Medicine 12, 1001834.

Institute for Health Metrics and Evaluation (IHME) (2015). GBD Compare. Seattle, WA: University of Washington. Retrieved 1 February 2016 from http://vizhub.healthdata.org/gbd-compare/.

Isaac M, Chand P, Murthy P (2007). Schizophrenia outcome measures in the wider international community. British Journal of Psychiatry 191, s71-s77.

Kane JM, Schooler NR, Marcy P, Correll CU, Brunette MF, Mueser KT, Rosenheck RA, Addington J, Estroff SE, Robinson J, Penn DL, Robinson DG (2015). The RAISE early treatment program for first-episode psychosis: background, rationale, and study design. Journal of Clinical Psychiatry 76, 240-246.

Kleinman A, Estrin GL, Usmani S, Chisholm D, Marquez PV, Evans TG, Saxena S (2016). Time for mental health to come out of the shadows. Lancet 387, 2274-2275.

Ley de Salud Mental Ley 1616 de 2013 (enero 21) (2013). Diario Oficial, 48680. http://wsp.presidencia.gov.co/ 
Normativa/Leyes/Documents/2013/LEY1616DEL21

DEENERODE2013.pdf.

Macinko J, Montenegro H, Adell CN, Etienne C (2007). La renovación de la atención primaria de salud en las Américas. Revista Panamericana d Salud Publica 21, 73-84. http://www.scielosp.org/scielo.php?script=sci_arttext\& pid=S1020-49892007000200003\&lng=es\&nrm=iso\&tlng=es.

Ministerio de Salud del Perú (2015). Ley No 29889. http:// www.elperuano.com.pe/NormasElperuano/2015/10/06/ 1296283-1.html.

Minoletti A, Galea S, Susser E (2012). Community mental health services in Latin America for people with severe mental disorders. Public Health Reviews 34, 1-23. Retrieved 17 April 2016 from http://www.pubmedcentral.nih.gov/ articlerender.fcgi? artid $=4203441 \&$ tool $=$ pmcentrez\& rendertype $=$ abstract.

Organización Panamericana de la Salud/Organización Mundial de la Salud (Ops/Oms) (1990). Declaración de Caracas. https://www.oas.org/dil/esp/Declaracion_ de_Caracas.pdf.

Panamerican Health Organization (PAHO) (2013). Brasilia Consensus http://www.paho.org/hq/index.php? option=com_content\&view=category \& layout=blog\&id=1170\& Itemid=940\&lang=en.

Panamerican Health Organization (PAHO) (2016). Background and Historical Development of PAHO Mental Health Program. Retrieved 18 April 2016 from http://www. paho.org/hq/index.php?option=com_content\&view= article\&id $=11660 \% 3$ Ahistoria-salud-mentalops\&catid $=8190 \% 3$ Acontents\&Itemid $=41733 \&$ lang $=$ en .

Razzouk D, Sharan P, Gallo C, Gureje O, Lamberte EE, de Jesus Mari J, Mazzoti G, Patel V, Swartz L, Olifson S, Levav I, de Francisco A, Saxena S (2010).
Scarcity and inequity of mental health research resources in low-and-middle income countries: a global survey. Health Policy 94, 211-220.

Razzouk D, Gregório G, Antunes R, Mari JD (2012). Lessons learned in developing community mental health care in Latin American and Caribbean countries. World Psychiatry 11, 91-95.

Rehm J, Monteiro M (2005). Alcohol consumption and burden of disease in the Americas: implications for alcohol policy. Revista Panamericana de Salud Pública 18, 241-248.

Silove D, Ward PB (2014). Challenges in rolling out interventions for schizophrenia. Lancet 383, 1362-1364.

The World Bank (2015). GINI Index. Retrieved 23 June 2016 from http://data.worldbank.org/indicator/SI.POV.GINI.

Wagstaff A, Dmytraczenko T, Almeida G, Buisman L, Hoang-Vu Eozenou P, Bredenkamp C, Cercone JA, Diaz Y, Maceira D, Molina S, Paraje G, Ruiz F, Sarti F, Scott J, Valdivia M, Werneck H (2015). Assessing Latin America's progress toward achieving universal health coverage. Health Affairs (Millwood) 34, 1704-1712.

Whiteford HA, Degenhardt L, Rehm J, Baxter AJ, Ferrari AJ, Erskine HE, Charlson FJ, Norman RE, Flaxman AD, Johns N, Burstein R, Murray CJ, Vos T (2013). Global burden of disease attributable to mental and substance use disorders: findings from the Global Burden of Disease Study 2010. Lancet 382, 1575-1586.

World Health Organization (WHO) (2013). Global and Regional Estimates of Violence Against Women: Prevalence and Health Effects of Intimate Partner Violence and Non-partner Sexual Violence. Geneva, Switzerland: World Health Organization.

World Population Prospects (2015). The 2015 Revision. https://esa.un.org/unpd/wpp/DataQuery/ 